\title{
MURAJA'AH LEARNING METHOD ON HOME TAHFIZH QUR'AN AN-NUUR
}

\section{METODE PEMBELAJARAN MURAJA'AH PADA RUMAH TAHFIZH QUR'AN AN-NUUR}

\author{
Feni Mercellina' ${ }^{1}$ Muhammad Adil'2, Karoma ${ }^{3}$ \\ ${ }^{1}$ UIN Raden Fatah Palembang \\ 2, 3 UIN Raden Fatah Palembang \\ fenimarcellina@gmail.com \\ muhammadadil_uin@radenfatah.ac.id \\ karoma1963@gmail.com
}

\section{Received: 19/04/2020, Accepted: 25/08/2020, Published: 29/08/2020}

\begin{abstract}
This study is aimed to analysis how the implementation of muraja'ah method to keep the Holy Qur'an memorization and the factors that influence its processes of implementing Qur'an learning method at Tahfizh Qur'an An-Nuur Sekayu.The type of this study is a field research. This study is presented in a descriptive qualitative method with the aim to describe a process occurs in the field setting. The approach applied in this study is a qualitative approach. Data collection techniques used are including: interview, observation and documentation methods. To analyze the data obtained from the results of the study, the writer used Miles and Huberman's interactive model data analysis techniques. Whereas to obtain data validity is determined by four criteria, namely the level of credibility, transferability, dependability, and confirmability. The results of the study are (1). The implementation of the Holy Qur'an learning at Tahfizh Qur'an An-Nuur Sekayu emphasizes the students to always apply muraja'ah method to keep the memorization of the Holy Quran. (2). Some factors that influence the implementation process of Tahfizh Qur'an learning are including: internal factors (the spirit within the students, health of students, intelligence, interests and motivation) and external factors (support from parents, teachers and friends).

Keywords: learning methods, muraja'ah, tahfizh Quran.
\end{abstract}

\begin{abstract}
ABSTRAK
Penelitian ini bertujuan untuk menganalisis bagaimana pelaksanaan metode pembelajaran muraja'ah dalam menjaga hafalan $\mathrm{Al}$-Qur'andan faktor-faktor yang mempengaruhi proses pelaksanaan pembelajaran tahfizh Al-Qur'an di Rumah Tahfizh Qur'an An-Nuur Sekayu. Jenis penelitian ini adalah penelitian lapangan. Penelitian ini disajikan dalam bentuk deskriptif kualitatif dengan tujuan untuk menggambarkan suatu proses yang terjadi di lapangan. Pendekatan yang dilakukan adalah pendekatan kualitatif. Teknik pengumpulan data yang digunakan antara lain: metode wawancara, observasi dan dokumentasi. Untuk menganalisa data yang diperoleh dari hasil penelitian, penulis menggunakan teknik analisis data model interaktif Miles dan Huberman.Sedangkan untuk memperoleh keabsahan data ditentukan oleh empat kriteria yaitu tingkat kredibilitas, transferabilitas, dependabilitas, dan konfirmabilitas. Temuan yaitu (1). Pelaksanaan pembelajaran Rumah Tahfizh Qur'an AnNuur menekankan kepada santri untuk selalu menerapkan metode muraja'ah dalam menjaga hafalan Al-Qur'an. (2). Faktor yang mempengaruhi proses pelaksanaan pembelajaran Tahfizh Al-Qur'an antara lain: faktor internal (semangatsantri, kesehatan santri, intelegensi, minat dan motivasi) dan faktor eksternal (dukungan orang tua, guru dan teman).
\end{abstract}

Kata kunci: metode pembelajaran, muraja'ah, tahfizh Al-Qur'an. 


\section{A. PENDAHULUAN}

Pendidikan Islam tidak bisa dipisahkan dengan gagasan dan program modernisasi Islam (Saihu, 2015: 3). Pada dasawarsa terakhir perkembangan pembelajaran tahfizh Al-Qur'an berkembang sangat pesat. Berdasarkan penelitian yang berjudul The Development of Tahfizh Alquran Movement in The Reform Era in Indonesia. Dikemukakan bahwa salah satu indikator dalam penelitian tersebut yang membuat semakin berkembangnya di Indonesia kegiatan menghafal Al-Qur'an adalah dengan adanya rumah tahfizh Al-Qur'an di setiap kota yang dicetuskan langsung oleh Daarul Qur'an binaan KH. Ustadz Yusuf Mansur. Sudah ada 300 lembaga di Indonesia yang dinaungi oleh Rumah Tahfizh Daarul Qur'an (Sofyan 2015).

Rumah tahfizh Al-Qur'an didirikan dengan konsep "jemput bola", berbeda dengan konsep pondok pesantren, hadir di antara masyarakat muslim sehingga mempermudah dalam pengembangan potensi terutama anak-anak dan remaja dalam menghafal dan mempertahankan hafalan Al-Qur'an. Dalam penelitian Atabik menyebutkan The Living Quran: Potret Budaya Tahfizh Al-Qur'an di Nusantara bahwa untuk menyelesaikan hafalan AlQur'an30 juz di pondok pesantren memerlukan waktu sekitar 2 sampai 4 tahun
(Tabik 2014). Dalam proses menghafal AlQur'an rentang waktu yang tersebut tergolong lama. Oleh sebab itu, dicetuskannya rumah tahfizh Al-Qur'an dengan program untuk mempercepat hafalan Al-Qur'an, yakni mempunyai target hafalan 30 juz Al-Qur'an hanya dalam waktu 3 tahun saja yang diistiqomahkan dengan menghafal minimal satu hari satu ayat. Sehingga lembaga-lembaga pendidikan Al-Qur'an di Indonesia sudah banyak tertarik dengan konsep rumah tahfizh Al-Qur'an dan mengadopsinya.

Rumah Tahfizh Qur'an An-Nuur sebagai wadah untuk mempermudah pembelajaran Al-Qur'an, dan mengajak umat Muslim terutama anak-anak dan remaja untuk belajar dan menghafalAlQur'an. Sudah berdiri 3 tahun yang lalu sampai saat ini tidak sepi peminat mulai dari usia tingkat sekolah dasar, usia tingkat SMP, usia tingkat SMA dan umum. Sampai saat inisudah tersebar di seluruh dunia rumah tahfizh Al-Qur'an dari pergerakan Darul Qur'an. Hal ini merupakan salah satu bentuk perjuangan untuk mengembalikan manusia kepada Al-Qur'an.

Harapan yang paling utama dalam proses pembelajaran di Rumah Tahfizh Qur'an An-Nuur adalah santri dapat mencapai tujuan belajar yakni menghafal Al-Qur'an dan istiqomah dalam menjaga 
hafalan, sekaligus pula memberikan dasar yang kuat membangun pendidikan (Saihu, 2019: 72). Sehingga dapat mencapai pembelajaran yang maksimal dalam menghafal Al-Qur'an selalu disempurnakan dan diperbarui dari masa ke masa (AlHamad, 2014).

Berkaitan dengan proses pembelajaran yang sedang diteliti, ditemukan fakta bahwa selama ini santri Rumah tahfizh Qur'an An-Nuur Sekayu mengalami kesulitan dalam menjaga hafalan Al-Qur'an yang telah dihafal terutama hafalan lama, sehingga hafalan santri tidak terjaga dan terlupa.

Hasil penelitian yang dilakukan oleh Nasution tentang penggunaan metode pembelajaran dalam meningkatkan hasil belajar dimana hasil belajar yang baik dapat dihasilkan dari proses pembelajaran yang baik. Dan proses pembelajaran yang baik diperoleh dari kemampuan tenaga pendidik dalam menerapkan metode pembelajaran yang sesuai dengan kebutuhan di dalam kelas (Nasution, 2017), Saihu juga mengungkapkan, pembelajaran dapat memberikan pandangan, wawasan dan keterbukaan kepada peserta didik, sebagai kekayaan dan potensi yang memberikan berkah kehidupan pada peserta didik. (Saihu, 2020: 137).

\section{B. TINJAUAN PUSTAKA \\ 1. Pengertian Metode Pembelajaran}

Metode berasal dari Bahasa Yunani methodos yang artinya cara atau jalan yang ditempuh. Metode merupakan cara yang dikerjakan secara sistematis. Pembelajaran adalah interaksi antara guru dan siswa dalam menggunakan sumber belajar baik di kelas maupun di luar (Poedjiadi, 2005). Metode pembelajaran adalah suatu cara yang dilakukan guna menerapkan rencana yang telah tersusun agar tercapai tujuan secara optimal (Sanjaya, 2008). Metode pembelajaran adalah cara yang khas dalam memanfaatkan prinsip pembelajaran, teknik dan sumberdaya yang terkait agar dalam diri pembelajar dapat terjadi proses pembelajaran (Ginting, 2008). Metode pembelajaran merupakan cara guru dalam menyajikan materi pembelajaran agar mudah diserap, dimanfaatkan dan dipahami murid (Prastya, 2005).

Metode pembelajaran adalah sebuah carayang digunakan pendidik supaya melakukan interaksiterhadap peserta didik pada saat pembelajaran berlangsung (Sudjana, 2000). Metode pembelajaran sebagai pelicinagar tercapainya tujuan pembelajaran yang diinginkan, oleh karena itu metode pembelajaran yang baik yaitu metode yang dapat menciptakan proses pembelajaran (Thaha, 2004). 
Pembelajaran adalah teknik yang dilakukan oleh guru untuk berinteraksi dengan siswa pada saat proses pembelajaran (Hamdani, 2011).

Dengan demikian metode pembelajaran memiliki peran yang sangat penting sehingga dapat terbangun dengan baik dan berkualiatas, individu-individu yang beradab akan terbentuk dan pada akhirnya akan memunculkan kehidupan sosial yang bermoral (Saihu, 2020: 84), karena keberhasilan pembelajaran sangat tergantung pada metode pembelajaran yang diterapkan oleh guru yang dipengaruhi oleh siswa, situasi, kemampuan guru, menerapkan metode dan kemampuan metode dalam proses pembelajaran.

\section{Pengertian Tahfizh Al-Qur'an}

Tahfizh Al-Qur'an merupakan upaya mendekatkan umat Muslim kepada kalamullah, agar selalu bersama Al-Qur'an (Hafizh, 2004).

\section{Pengertian Metode Pembelajaran Tahfizh Al-Qur'an}

Metode pembelajaran tahfizh Al-Qur'an merupakan kerangka konseptual yang menjadi pedoman dalam proses pembelajaran yang dilakukan guru dalam mendekatkan orang yang beriman kepada Al-Qur'an.

\section{Pengertian Metode Muraja'ah}

Metode muraja'ah adalah carauntukmengulang hafalan Al-Qur'an agar selalu terjaga. Mengulang hafalan bisa bersama dengan teman, mengulang ketika shalat dan dengan guru (Anwar, 1997). Bacalah berulang-ulang ayat yang mau dihafal sebanyak 35 kali pengulangan sebelum mulai menghafal. Karena ini merupakan cara mudah untuk merekam terlebih dahulu ayat-ayat tersebut. Dan butuh waktu cukup lama (Hafizh, 2004). Bahwa muraja'ah yang membuat seseorang kuat dalam bidang tahfizh. Dalam menghafal Al-Qur'an ada tiga macam metodemuraja'ah yang efektif yaknimuraja'ahsendiri, muraja'ah bersama teman, dan muraja'ah bersama ustadzh (Hurri, 2010).

Jadi metode muraja'ah suatu cara untuk mengulang kembali hafalan AlQur'an yang telah dihafal agar hafalan tetap terjaga.

\section{METODE PENELITIAN}

Jenis penelitian ini merupakan penelitian lapangan, karena data yang diperoleh langsungberasal dari objek yang bersangkutan (Moleong, 2011). Subjek penelitian ini adalah kegiatan di Rumah Tahfizh Qur'an An-Nuur Sekayu dan pengaruhnya terhadap menjaga hafalan AlQur'an santri. Pendekatan penelitian deskriptif kualitatif. Karena data dikumpulkan berupa gambar, kata-kata dan 
bukan untuk angka. Adapun sumber data berupa kata-kata dan tindakan, sumber tertulis dan foto. Metode pengumpulan data melalui wawancara, observasi langsung dan dokumentasi. Selain itu proses penggalian data dilakukan pada suatu bentuk kondisi alamiah tanpa ada rekayasa maupun intervensi. Teknik analisis yang digunakan dalam penelitian ini adalah teknik data model interaktif Miles dan Huberman. Sedangkan untuk memperoleh keabsahan data ditentukan oleh empat kriteria yaitu tingkat kredibilitas, transferabilitas, dependabilitas, dan konfirmabilitas. Dalam penelitian kualitatif analisis data lebih difokuskan selama proses dilapangan bersama dengan pengumpulan data (Sugiyono, 2016).

\section{PEMBAHASAN}

\section{Sejarah Singkat}

Rumah Tahfizh Qur'an An-Nuur Binaan langsung KH. Ustadz Yusuf Mansyur merupakan program yang digagas oleh Pesantren Tahfizh Daarul Qur'an dan telah diresmikan pengurus yakni mulai kegiatan belajar pertama oleh H. Qotruddin pada hari Senin, tanggal 19 Desember 2016. Rumah Tahfizh ini berlokasi di Jalan Merdeka Lk. I. RT. 005 RW. 002 No. 097 Kompleks SD Negeri 3 Sekayu, Kelurahan
Serasan Jaya Kecamatan Sekayu Kabupaten Musi Banyuasin, Kode Pos 30711.

\section{Pelaksanaan Metode Muraja'ah}

Berdasarkan hasil wawancara dan observasi di Rumah Tahfizh Qur'an AnNuur Sekayu, sebagai berikut: Santri memiliki kelas masing-masing sesuai dengan tingkat hafalan, santri melakukan muraja'ah setiap hari setelah setoran hafalan baru ke ustadzh, dan ada satu hari hanya khusus untuk muraja'ahhafalan yaitu hari Jum'at. Hari Jum' at seluruh santri pada setiap kelompok masing-masing melakukan muraja'ah secara bersama Metode muraja'ah Rumah Tahfizh Qur'an AnNuurmemiliki istilah dalam hal muraja'ah yakni tasmi' (Celebrationmuraja'ah). Tasmi' adalah memperdengarkan muraja'ah hafalan di depan umum kepada seluruh teman-teman, guru dan orang tua santri. Tasmi' dilakukan oleh setiap santri yang sudah menuntaskan 1 juz hafalannya yang diikuti oleh seluruh teman kelompok hafalan. Pada saat pelaksanaan tasmi' didampingi oleh ustadz dan ustadzah, mengoreksi hafalan santrijika keliru baik dari segi makhraj maupun tajwidnya atau jika santri lupa kelanjutan ayatnya.

Kegiatan tasmi' bertujuan untuk membiasakan santri untuk tampil di depan umum dengan memperdengarkan hafalan Al-Qur'an yang telah dihafal dengan 
semaksimal mungkin. Tasmi' terkadang dijadikan sebagai penyemangat bagi santri dalam menuntaskan hafalan 1 juz, karena selain sudah menuntaskan 1 juz santri juga sering mendapatkan hadiah dari orang tua mereka sendiri.

Tujuan diterapkannya metode muraja'ah yakni:

a). sebagai bentuk usaha seorang santri penghafal Al-Qur'an dalam menjaga hafalannya seumur hidup.

b). supaya santri lebih merasa prihatin terhadap hafalannya ketika hafalannya mulai kurang lancar dan lebih meluangkan waktu untuk melaksanakan muraja'ah agar hafalan tersebut tetap terjaga dan utuh seumur hidup.

Adapun kegiatan dalam pembelajaran yang digunakan di Rumah Tahfizh Qur'an An-Nuur Sekayu, sebagai berikut:

\section{a). Metode Talaqqi}

Dilakukan talaqqi yaitu tes perorangan dalam membacakan Al-Qur'an untuk melihat tingkat kemajuan bacaan santri.

\section{b). Metode Juz 30 Lebih Dahulu}

Santri diarahkan untuk menghafal juz 30 terlebih dahulu sebelum menghafal juz 1 maupun juz 2 dan seterusnya.

\section{c). Metode Pengulangan Ayat Per Halaman}

Santri menghafal dengan mngulang-ulang bacaan seluruh ayat pada satu halaman mushaf, kemudian selanjutnya menghafalkan. Pengulangan paling cepat membutuhkan waktu sekitar 15 menit bahkan ada yang 10 menit.

\section{d). Per Ayat}

Santri menghafalkanAl-Qur'an ayat demi ayat pada surat yang akan dihafalkan. Jika satu persatu ayat sudah dihafalkan, maka dilanjutkan menghafal ayat berikutnya.

\section{e). Metode Menirukan Bacaan Ustadz}

Ada beberapa halaqah yang menggunakan metode ini. Ustadz membacakan terlebih dahulu ayat yang ingin dihafalkan kemudian diikuti oleh santri.

\section{f). Metode One Day One Ayat}

Hanya ada beberapa santri yang menghafal dan setoran satu hari satu ayat saja. Ini cara yang paling rendah dapat dilakukan, karena jika satu hari satu ayat maka butuh waktu 17 tahun lebih dapat menghafalkan 30 juz Al-Qur'an.

\section{g). Mengikuti Halaqah Terus Menerus}

Saat peneliti mengambil data dan melakukan observasi di Rumah Tahfizh Qur'an An-Nuur Sekayu, peneliti melihat para santri antusias dan semangat mengikuti halaqah. 


\section{h). Muraja'ah berkala}

Peneliti mengamati kegiatan santri di dalam musholla rumah tahfizh yang merupakan tempat kegiatan belajar mengajar mereka intensif muraja'ah hafalan mandirimasingmasing. Di mana-mana selalu terdengar lantunan ayat suci Al-Qur'an. Rata-rata yang dimuraja'ah adalah minimal sepuluh halaman bagi yang sudah memiliki hafalan Al-Qur'an 1 Juz. Serta kebanyakan santri memuraja'ah hafalan dengan melihat mushaf. Sehingga durasi waktu dalam muraja'ah hafalan terbilang cepat jika dibandingkan dengan muraja'ah dengan tanpa melihat mushaf yakni masing-masing di antara mereka hanya membutuhkan waktu setengah jam bahkan sampai satu jam.

\section{i). Muraja'ah dalam Shalat Sunnah}

Satu jam sebelum adzan Ashardan adzan maghrib dikumandangkan kegiatan belajar mengajar sudah di mulai, santri datang ke masjid dengan membawa Al-Qur'an masing-masing. Setiba di masjid masingmasing mereka menghafal dan memuraja'ah hafalan, ketika adzan berkumandang suara mereka diam dan sepi. Kemudian setelah adzan selesai mereka melakukan sholat sunah, dan rata-rata sholat sunnah mereka di rakaat pertama dan rakaat kedua memiliki durasi waktu yang panjang atau lama berdiri. Hal ini ternyata mereka membaca ayat yang mereka hafal hingga satu halaman Al-Qur'an.

\section{j). Sima’ Bersama Teman}

Peneliti menghampiri mereka yang duduk berdua saling berhadapan, ternyata mereka lagi melakukan sima' hafalan. Dalam waktu luang hal ini sering mereka manfaatkan.

\section{k). Mushaf Standar}

Peneliti melihat dan mengecek Al-Qur'an yang mereka gunakan, ternyata semuanya rata-rata memakai Al-Qur'an standar Madinah.Al-Qur'anstandar Madinah memiliki 604 halaman, setiap awal ayat selalu berada di sudut atas setiap halaman Al-Qur'an, dan akhir ayat selalu berada di sudut bawah setiap halaman.

\section{l). Punishment}

Punishment merupakan sebuah bentuk hukuman yang diberikan oleh ustadz bagi santri yang apabila melakukan kesalahan dalam halaqah, seperti ngobrol, dan mainmain. Punisment yang diberikan berupa berdiri sambil menghafal ayat baru dan muraja'ah sampai batas waktu yang ditentukan.

\section{Faktor-faktor yang Mempengaruhi Proses Pelaksanaan Pembelajaran Tahfizh Al-Qur'an}

Suatu program yang diterapkan akan mengalami pasang surut, program akan berjalan dengan lancar dan terhendat oleh sesuatu. Adapun mengenai metode muraja'ah merupakan suatu program yang 
diterapkan di Rumah Tahfizh Qur'an AnNuur Sekayu. Maka program ini pun memiliki faktor-faktor yang mendukung lancarnya metode ini, begitupula dengan faktor penghambat metode muraja'ah berjalan kurang lancar. Berikut ini hasil wawancara dan observasi tentang faktor pendukung dan penghambat, di antaranya sebagai berikut:

\section{1). Faktor Pendukung}

Faktor pendukung yaitu, Orang tua, guru, dan teman. Faktor-faktor pendukung ini berasal dari luar dan dari dalam diri santri.

Berikut ini penjelasan mengenai faktor pendukung diantaranya yaitu: a). Faktor Pendukung dari dalam diri (Internal). 1). Semangat santri, jika santri semangat untuk menjaga hafalan dengan rajin memuraja'ah maka hasilnya akan maksimal karena yang namanya hafalan harus keluar dari kemauan sendiri. 2). Kesehatan santri, merupakan salah satu pendukungnya, jika santri tidak memilik rasa nyaman dan kurang sehat pada hari itu maka muraja'ah tidak terlaksana dengan efektif dan efisien. Kondisi santri yang kurang maka santriakan merasa tidak nyaman dalam melakukan muraja'ah. 3). Intelegensi (IQ), Intelegensi santri merupakan salah satu faktor pendukung dalam melakukan muraja'ah, setiap IQ santri yang normal maka akan memudahkan melakukan muraja'ah, karena mereka memiliki ingatan yang kuat. 4). Minat dan motivasi. Santri yang memiliki minat dan motivasi yang tinggi maka santri akan melakukan semua proses kegiatan belajar dengan senang dan gigih dalam melakukannya. b). Faktor Pendukung dari luar (Eksternal). 1). Orang tua, orang tua meruapakan orang yang paling dekat dengan santri, maka orang tua juga memiliki tugas mengontrol anak-anaknya baik itu dalam hafalan santri. Terlebih lagi jika santri melakukan muraja'ah. Maka orang tua siswa harus membantu anak untuk melakukan segala kesulitan yang dihadapi santri dalam pelajaran maupun dalam hal sosisal anak. Orang tua santri merupakan faktor luar yang menjadi pendukung santri untuk melakukan muraja'ah. Jika faktor orang tua dan perhatiannya terhadap santri kurang, maka santriakan mengalami kesulitan ketika melakukan muraja'ah hafalan yang sebelumnya. Orang tua berfungsi untuk membantu santri melakukan muraja'ah di rumah. Karena muraja'ah tidak hanya dilakukan di rumah tahfizh, muraja'ah di rumah menunjang kelancaran santri melakukan muraja'ah di rumah tahfizh. Sehingga orang tua santri sangat berperan dalam melakukan muraja'ah santri di rumah. Adapun orang tua memiliki peran yang sangat penting dalam membantu santri 
untuk muraja'ah hafalannya ketika di rumah. Sehingga muraja'ahyang dilakukan di rumah tahfizh menjadi lancar dengan melakukan muraja'ahdi rumah sebelumnya dengan bantuan orang tua.2). Guru, guru merupakan orang tua kedua bagi santri sehingga guru juga merupakan faktor pendukung. Guru sebagai fasilitator santri dalam melakukan muraja'ah. 3). Teman, teman adalah salah satu pengaruh besar bagi santri jika memiliki teman yang pergaulan baik maka santriakan mencerminkan prilaku yang baik, sebaliknya jika santri begaul dengan teman yang pergaulannya buruk, maka santri akan mencerminkan prilaku yang buruk. Maka dari itu santri harus pandai dalam memilih teman bergaul dalam kehidupan sehari-hari.

\section{2). Faktor Penghambat}

Faktor penghambatyaitu: a). Keterbatasan waktu, waktu muraja'ah di rumah tahfizh sangatlah terbatas sehingga muraja'ah santri jadi tertunda pada hari itu. Maka waktu sangatlah penting untuk dimanfaatkan guru sebaik mungkin. b). Kurangnya kumber daya guru, sumber daya guru yang sedikit membuat waktu muraja'ahmenjadi tidak efektif untuk. c). Kondisi santri, kondisi santri yang kurang stabil dalam artian emosional santri yang tinggi atau kesehatan santri yang kurang sehat sehingga membuat proses pembelajaran tidak nyaman berdampak untuk tidak mau melakukan muraja'ah hafalan.

Hambatan-hambatan yang dilalui oleh calon hafizh dan hafidzah yakni merasa sibuk, hati merasa kotor, dan kurang fokus disebabkan masalah pribadi, jenuh serta merasa berat di saat mau menghafal atau di tengah hafalan, faktor umur, ingatan yang lemah sehingga takut lupa dan merasa pendosa serta tidak yakin dengan kemampuan diri sendiri dalam menghafal Al-Qur'an (Zawawie, 2000).

Setiap jalan menuju kebaikan pasti terdapat rintangan yang menghalangi untuk mencapai tujuan. Menghafal Al-Qur'an merupakan kegiatanyang sangat mulia, baik dihadapan Allah S.W.T. dan pandangan manusia. Karena banyak waktu yang harus dikorbankan, konsentrasi pikiran yang terfokus untuk menghafal Al-Qur'an, serta tenaga danbiaya juga ikut dikorbankan. Semua semata-mata hanya mengharap ridho Allah S.W.T. tidak ada hasrat sedikitpun menjadikannya sebagai sumber penghasilan ataupun pujian. Dibalik kemuliaan tersebut, terdapat duri godaan yang bisa datang dengan tiba-tiba. Jadi, siapapun yang pernah menjalani proses menghafal Al-Qur'an dipastikan pernah merasakanpahitnya cobaan dan manisnya godaan. Tentu, jenis cobaan dan 
godaantiap-tiap orang berbeda. Adapun kemampuan menghadapi godaan tersebut berbeda-beda tergantung ketulusan niat dan kedalaman iman (Qurani 2010).

Terdapat solusi untuk mengatasi faktor penghambat tersebutsebagai berikut:

\section{a). Istiqamah Muraja'ah}

Untuk menjaga hafalan supaya terjaga dengan baik dan lancar dapat dilakukan dengan muraja'ah, yaitu santri harus rajin mengulang hafalan secara istiqamah. Melakukan muraja'ah dapat dilakukan sendiri maupun dengan teman sesama penghafal Al-Qur'an.

\section{b). Manajemen Waktu}

Santri halaqah tahfizh di Rumah Tahfizh Qur'an An-Nuur Sekayu mereka menghafal Al-Qur'an sambil sekolah. Jadi sangat diperlukan dalam memanajemen waktu yang baik antara mengerjakan tugas sekolah serta menambah hafalan dan muraja'ah.

\section{E. KESIMPULAN}

Dari hasil penelitian dan pembahasan tersebut dapat disimpulkan:

\section{Pelaksanaan Metode Muraja'ah}

Santri memiliki kelas masing-masing sesuai dengan tingkat hafalan, setiap hari sesudah setoran hafalan Al-Qur'an ke ustadz ustadzah santri melakukan muraja'ah dan semua halaqah memiliki satu hari hanya khusus untuk muraja'ah hafalan saja yaitu hari Jum'at. Metode muraja'ah Rumah Tahfizh Qur'an AnNuur memiliki istilah dalam hal muraja'ah yakni tasmi'. Tasmi' dilakukan oleh setiap santri yang sudah menuntaskan 1 juz hafalannya yang diikuti oleh seluruh teman kelompok hafalan. Pada saat pelaksanaan tasmi' didampingi oleh ustadz dan ustadzah, mengoreksi hafalan santrijika keliru baik dari segi makhraj maupun tajwidnya atau jika santri lupa kelanjutan ayatnya. Kegiatan tasmi' bertujuan untuk membiasakan santri untuk tampil di depan umum dengan memperdengarkan hafalan Al-Qur'an yang telah dihafal dengan semaksimal mungkin.

2. Faktor-faktor yang Mempengaruhi Proses Pelaksanaan Pembelajaran Tahfizh Al-Qur'an

1). Faktor Pendukung yaitu, Orang tua, guru, dan teman. Faktor-faktor pendukung ini berasal dari luar dan dari dalam diri santri. Berikut ini faktor pendukung yaitu: a). Faktor Pendukung dari dalam diri (Internal). 1). Semangat santri. 2). Kesehatan santri. 3). Intelegensi (IQ). 4). Minat dan motivasi. b). Faktor Pendukung dari luar (Eksternal). 1). Orang tua. 2). Guru. 3). Teman. 
2). Faktor Penghambat yaitu: a). Keterbatasan waktu. b). Kurangnya sumber daya guru. c). Kondisi santri.

\section{DAFTAR PUSTAKA}

\section{Sumber dari Jurnal}

Al-Hamad, Zameer Ahmaed Adhoni \& Husam Ahmed. (2014). A Cloud Quran Application Using Drupal Technology. International Journal of Web Application, 6(1).

Nasution, M.K. (2017). Penggunaan Metode Pembelajaran dalam Peningkatan Hasil Belajar Siswa. Studi Didaktika. Jurnal Ilmiah Bidang Kependidikan, 11(1).

Saihu. (2015). Modernisasi Pendidikan Islam di Indonesia. Al Amin: Jurnal Kajian Ilmu dan Budaya Islam, 3(1).

Saihu. (2019). Pendidikan Karakter Berbasis Kearifan Lokal (Studi di Jembrana Bali). Edukasi Islami: Jurnal Pendidikan Islam, 08(01).

Saihu. (2020). Implementasi Metode Pendidikan Pluralisme dalam Mata Pelajaran Pendidikan Agama Islam. Belajea: Jurnal Pendidikan Islam, $5(01)$.

Saihu. (2020). Konsep Pembaharuan Pendidikan Islam Menurut Fazlurrahman. Andragogi: Jurnal Pendidikan Islam, 2(1).

Sofyan, M. (2015). The Development of Tahfizh Alquran Movement in The Reform Era in Indonesia. International Journal of Religions Literatur and Heritage, 4(1).
Tabik, A. (2014). The Living Quran: Potret Budaya Tahfizh Alquran di Nusantara. Jurnal Penelitian, 8(1).

\section{Sumber dari Buku}

Anwar, Thahar Yusuf dan Saiful. (1997). Metodologi Pengajaran Agama dan Bahasa Arab. Jakarta: PT RajaGrafindo Persada.

Ginting, A. (2008). Esensi Praktis Belajar dan Pembelajaran. Bandung: Humaniora.

Hafizh, Abdul Aziz Abdul Rauf Al. (2004). Kiat SuksesMenjadi Hafizh Qur'an. Bandung: Syaamil Cipta Medika.

Hamdani. (2011). Strategi Belajar Mengajar. Bandung: Pustaka Setia.

Hurri, A. (2010). Cepat dan Kuat Hafal Juz'amma. Sukoharjo: Al-Hurri Media Qur'anuna.

Moleong, L.J. (2011).Metodologi Penelitian Kualitatif. Bandung: PT Remaja Rosdakarya.

Poedjiadi, Anna. (2005).Sains dan Teknologi Masyarakat. Bandung: PT Remaja Rosdakarya.

Prastya, Abu Ahmadi \& Joko Tri. (2005). Strategi Belajar Mengajar. Bandung: Pustaka Setia.

Cahaya Qurani. (2014). Wordpress.com. 3 Desember 2010. http://cahayaqurani.wordprees.com (diakses Mei 19).

Sanjaya, W. (2008). Strategi Pembelajaran Berorientasi Standar Proses Pendidikan. Jakarta: Prenada Media Group.

Sudjana, N. (2000). Dasar-dasar Proses Belajar Mengajar. Bandung: Sinar Baru Algensindo.

Sugiyono. (2016). Metode Penelitian Pendidikan. Bandung: Alfabeta. 
Thaha, C. (2004). Metodologi Pengajaran Agama. Yogyakarta: Pustaka Belajar.

Zawawie, M. (2000). Pedoman Membaca, Mendengar, dan Menghafal Alquran. Bandung: Pustaka Setia. 